\title{
Ecological niche model of Phlebotomus perniciosus, the main vector of canine leishmaniasis in north-eastern Italy
}

\author{
Manuela Signorini ${ }^{1}$, Rudi Cassini ${ }^{1}$, Michele Drigo ${ }^{1}$, Antonio Frangipane di Regalbono ${ }^{1}$, \\ Mario Pietrobelli ${ }^{1}$, Fabrizio Montarsi ${ }^{2}$, Anna-Sofie Stensgaard ${ }^{3,4}$ \\ ${ }^{1}$ Department of Animal Medicine, Production and Health, University of Padova, Legnaro, Italy; ${ }^{2}$ Istituto \\ Zooprofilattico Sperimentale delle Venezie, Legnaro, Italy; ${ }^{3}$ Center for Macroecology, Evolution and Climate, \\ the Natural History Museum of Denmark, University of Copenhagen, Copenhagen, Denmark; ${ }^{4}$ Department for \\ Veterinary Disease Biology, University of Copenhagen, Copenhagen, Denmark
}

\begin{abstract}
With respect to the epidemiology of leishmaniasis, it is crucial to take into account the ecoclimatic and environmental characteristics that influence the distribution patterns of the vector sand fly species. It is also important to consider the possible impact of on-going climate changes on the emergence of this disease. In order to map the potential distribution of Phlebotomus perniciosus, the main vector species of canine leishmaniasis in north-eastern Italy, geographical information systems tools, ecological niche models (ENM) and remotely sensed environmental data were applied for a retrospective analysis of an entomological survey conducted in north-eastern Italy over 12 years. Sand fly trapping was conducted from 2001 to 2012 in 175 sites in the provinces of Veneto, Friuli-Venezia Giulia and Trentino-Alto Adige. We developed a predictive model of potential distribution of P. perniciosus using the maximum entropy algorithm software, based on seasonal normalized difference vegetation index, day and night land surface temperature, the Corine land cover 2006, a digital elevation model (GTOPO30) and climate layers obtained from the WorldClim database. The MaxEnt prediction found the more suitable habitat for P. perniciosus to be hilly areas $(100-300 \mathrm{~m}$ above the mean sea level) characterised by temperate climate during the winter and summer seasons, high winter vegetation cover and moderate rainfall during the activity season of vector sand fly. ENM provided a greater understanding of the geographical distribution and ecological requirements of $P$. perniciosus in the study area, which can be applied for the development of future surveillance strategies.
\end{abstract}

Keywords: canine leishmaniasis, sand fly, Phlebotomus perniciosus, ecological niche models, geographical information systems, maximum entropy, Italy.

\section{Introduction}

Canine leishmaniosis (CanL) is a zoonotic parasitic disease caused by Leishmania infantum (Protozoa, Trypanosomatidae) and transmitted by phlebotomine sand flies with the domestic dog as the main reservoir host. The number of reported cases is increasing worldwide and the geographical range seems to be expanding, particularly in south and central Europe (Bogdan et al., 2001; Maroli et al., 2008; Dereure et al., 2009). In Europe, phlebotomine sand flies have been thought to be restricted to the Mediterranean area, but they have recently been caught also north of the Alps (Farkas et al., 2011; Naucke et al., 2011;

Corresponding author:

Manuela Signorini

Department of Animal Medicine Production and Health

University of Padova

Viale dell'Università 16, 35020 Legnaro, PD, Italy

Tel. +39049 827-2968

E-mail: manuela.signorini@studenti.unipd.it
Haeberlein et al., 2013). Since the 1990s, new foci of CanL have being detected in northern Italy, previously regarded as non-endemic. The disease has increased gradually in the alpine region and entomological surveys have demonstrated the established presence of two vectors of the disease, Phlebotomus perniciosus and P. neglectus in several localities of the area (Poglayen et al., 1997; Rossi et al., 1999; Ferroglio et al., 2002; Maroli et al., 2008; Morosetti et al., 2009). While the changing pattern of the disease has mainly been attributed to the movement/introduction of infected dogs from endemic areas, the latitudinal shift in vector distribution might be related to recent climatic changes and/or other environmental changes (e.g. urbanisation and deforestation) that impact their living conditions (Ferroglio et al., 2005; Ready, 2008; Fischer et al., 2010, 2011a; Maroli et al., 2012). The geographical distribution of the phlebotomine sand fly is known to be strongly linked to environmental conditions that can influence its presence and density, such as altitude, land cover, vegetation and climatic factors (e.g. temperatures and soil moisture) (Biocca et al., 
1977; Cross and Hyams, 1996; Alexander, 2000; Gebre-Michael et al., 2004; Belen and Alten, 2011; Pérez et al., 2013).

In this study, we used an ecological niche model (ENM) and a database based on 12-years of entomological surveys to develop a model for P. perniciosus in north-eastern Italy with special reference to the environmental factors influencing the distribution of this species. We chose the maximum entropy algorithm (MaxEnt) that has already used to build predictive model for sand fly and CanL studies in Europe (Chamaille et al., 2010; Fischer et al., 2011a,b) but so far only applied in Italy for arthropod vector ecological studies and mosquitoes species potentially involved in transmission of the West Nile virus (Mughini-Gras et al., 2013).

\section{Materials and methods}

\section{Study area}

The study area included three provinces of northeastern Italy: Veneto, Friuli-Venezia Giulia and Trentino-Alto Adige (Fig. 1). The area shows varied orographic and climatic features because of the coexistence of several microclimates influenced by the presence of the Alps and foothills, the Garda Lake, the lowlands (Pianura Padana) and the Adriatic Sea coast.
The altitudinal range varies from 0 to $3,900 \mathrm{~m}$ above the mean sea level (MSL); the climate is continental with hot summers exceeding $30^{\circ} \mathrm{C}$, particularly in the lowlands and generally cold winters with temperatures below $0{ }^{\circ} \mathrm{C}$ at high altitudes. In the flat areas of Pianura Padana, the temperatures can drop to values below $-10{ }^{\circ} \mathrm{C}$ and remain below $0{ }^{\circ} \mathrm{C}$ even during daytime. In contrast, the climate is near-Mediterranean in the areas adjacent to the Garda Lake. Precipitation varies depending on altitude and the prevailing winds. The highest levels of precipitation are found in the Alps, in particular in the Dolomites where rainfall may exceed 2,200 $\mathrm{mm} / \mathrm{year}$, whereas the plains receive considerably lower levels ranging between 600 and 800 $\mathrm{mm} /$ year.

\section{Entomological survey}

The study is based on data collected during a continuous, but not-uniform, sand fly monitoring activity conducted from 2001 to 2012 in response to the identification of new autochthonous foci of CanL in the study area. Trapping of this vector was performed during the sand fly activity seasons (June-October) in 175 geo-referenced sites. Overall, 114 sites were monitored repeatedly using sticky traps for two consecutive nights (using $447.20 \mathrm{~m}^{2}$ in all with an average of 3.92 $\mathrm{m}^{2} / \mathrm{site}$ ), 53 sites using CDC light traps (121 catch

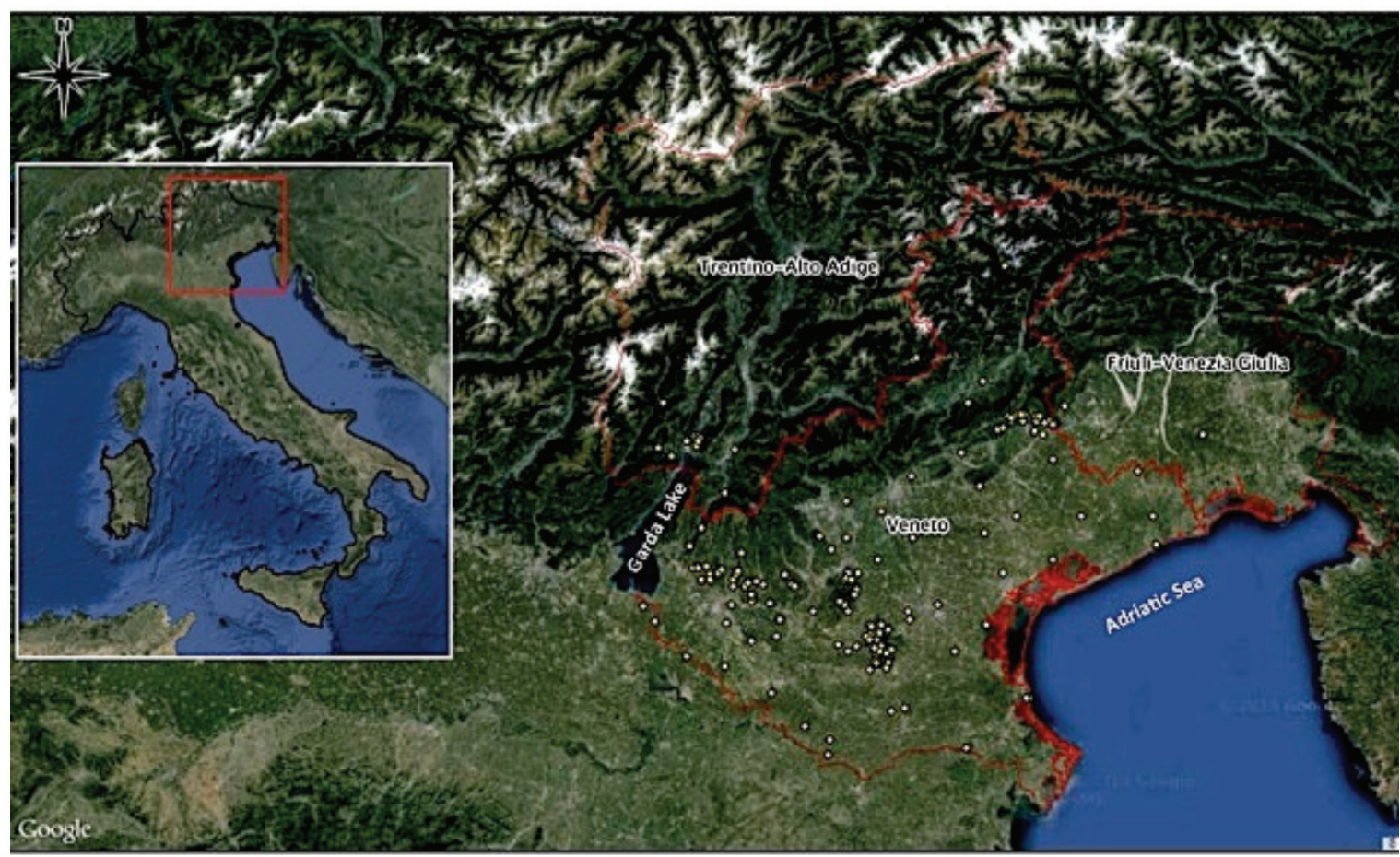

Fig. 1. Study area and entomological stations. 
nights in all with an average of 2.28 nights/site) and 66 sites by $\mathrm{CO}_{2}$ traps $(723$ catch nights in all with an average of 10.95 nights/site), whose detailed characteristics have been described previously (Signorini et al., 2013). The collected sand flies were stored in $70 \%$ ethanol and identified according to morphological features (Romi et al., 1994). The positions of the entomological stations are highlighted in Fig. 1.

Environmental layers and geographical information system (GIS) platform

Based on the biological and ecological knowledge on sand fly requirements, the environmental factors chosen as potential explanatory factors for P. perniciosus distribution were the following: altitude, slope, aspect, land cover, cover vegetation, day and night time temperature and rainfall.

Altitude was based on the digital elevation model (DEM) GTOPO30, obtained from the United States Geological Survey (USGS) Earth Resources Observation and Science (EROS) Data Center (http://rda.ucar.edu/datasets/ds758.0/); the aspect and slope layers were derived from the DEM through the use of the spatial analyses toolset of ArcGIS ${ }^{\circledR}$ software version 10.1 (ESRI; Redlands, USA).

Land cover was extracted from the Corine Land Cover 2006 raster map (CLC) from the European Environment Agency (http://www.eea.europa.eu/dataand-maps/data/corine-land-cover-2006-clc2006-100$\mathrm{m}$-version-12-2009\#tab-gis-data). This data is organised in 3-hierarchical levels and 44 classes, but only the higher-level classes were considered here and reclassified in the following six classes deemed relevant for the vectors ecology: artificial surfaces, arable land, permanent crops and pastures, heterogeneous agricultural areas, forest and semi-natural areas, wetlands and water bodies.

The normalized difference vegetation index (NDVI), often used as a surrogate for soil moisture (Wang et al., 2007) and the day and night land surface temperature $\left(\mathrm{LST}_{\text {day }}\right.$ and $\mathrm{LST}_{\text {night }}$ ) derived from the the Moderate Resolution Imaging Spectroradiometer (MODIS) onboard the Terra satellite (https://lpdaac. usgs.gov/), were downloaded and processed to create maps of the seasonal and annual averages of these parameters along the whole 12 -year period. The data were processed in $\mathrm{R}$, version 2.15.3 using the MODIS package (http://r-forge.r-roject.org/projects/modis/).

Rainfall estimates were obtained from the WorldClim database (http://www.worldclim.org) that are based on interpolated climate data from weather stations to produce average monthly rainfall data at a $1 \mathrm{~km}^{2}$ resolution. We used the following seven measures: annual precipitation (BIO 12), precipitation of the wettest month (BIO 13), precipitation of the driest month (BIO 14), precipitation of the wettest quarter (BIO 16), precipitation of the coldest quarter (BIO 17), precipitation of the warmest quarter (BIO 18) and precipitation of the driest quarter (BIO 19) when constructing the model. A geo-database was built, by creating $1-\mathrm{km}$ buffer zones centred on each site and extrapolating the mean values for all considered environmental features within each buffer zone, using the geospatial modelling environment (http://www.spatialecology.com/gme/) and ARC GIS ${ }^{\circledR}$.

\section{Model building and evaluation}

The map of potential distribution of P. perniciosus was developed by applying an ecological niche modelling (ENM) approach and the algorithm of maximum entropy was chosen, using MaxEnt, version 3.3.3k (http://www.cs.princeton.edu/schapire/maxent/). MaxEnt estimates species distributions by finding the distribution of maximum entropy (most spread-out or closest to uniform) subject to constraints imposed by the information available regarding the observed distribution of the species and environmental variables entered into the model building process across the study area (Phillips et al., 2006; Phillips and Dudík, 2008). The MaxEnt method requires presence-only species' data and uses background environmental data for the entire study area. MaxEnt's predictive performance is consistently competitive with the highest performing methods (Elith et al., 2006) particularly with small, incomplete and irregular species occurrence data sets (Hernandez et al., 2006; Pearson et al., 2007; Loiselle et al., 2008).

In order to develop the model, only the 60 sites positive to the presence of three or more specimens of P. perniciosus were used (Fig. 2). This choice was made to strengthen the predictive ability of the model, since the presence of one or two specimens may also result from errors during the sampling activity. Seventy-five percent of the data points were randomly selected as training points $(n=45)$, used in model building. The remaining $25 \%$ of the records were used as test points $(n=15)$ for model validation. Duplicate presence records were removed by the MaxEnt software prior to model development and random seed was applied. The MaxEnt model output was set to logistic, which returns an estimated relative probability of presence at a given location ranging from 0 (indi- 


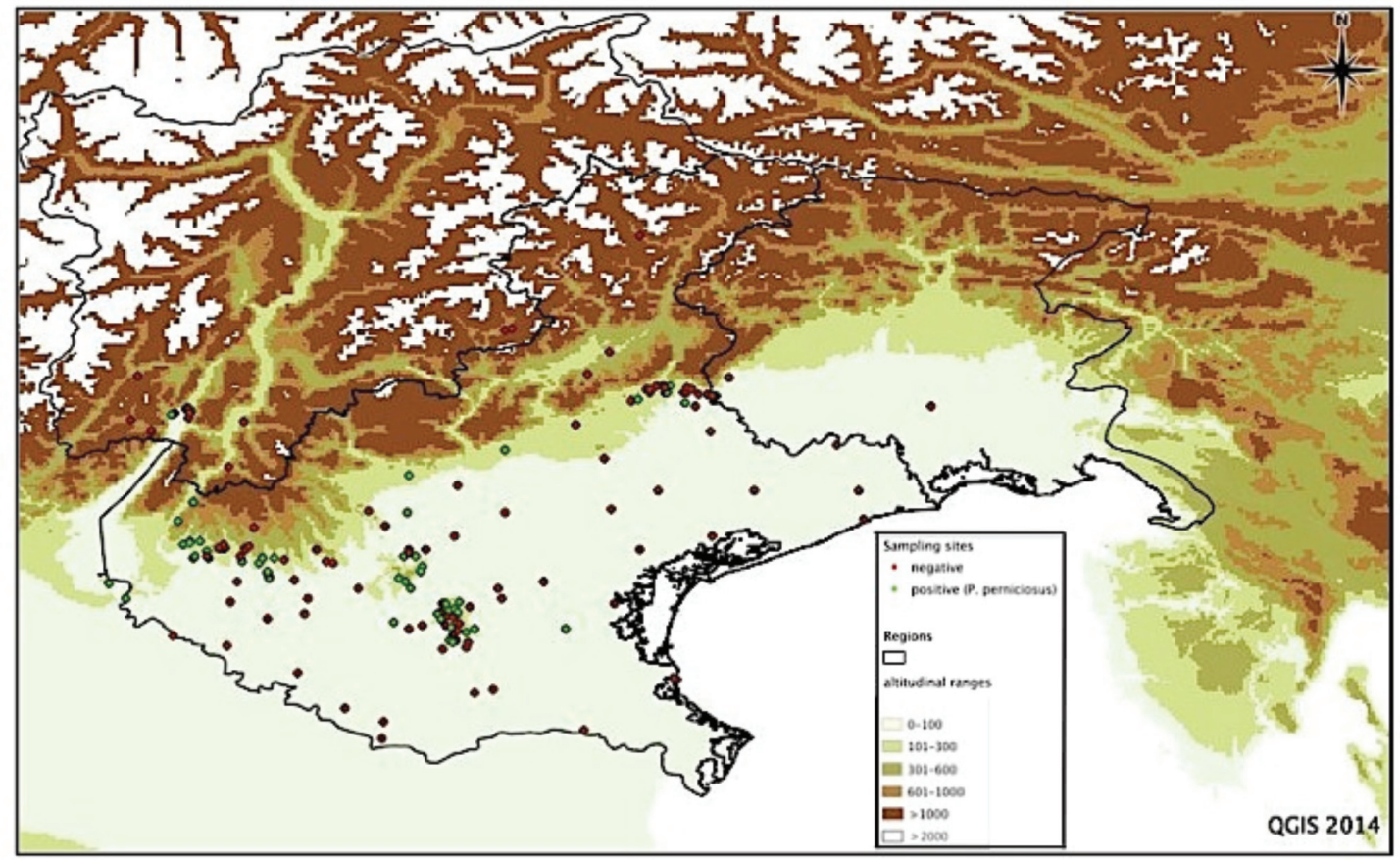

Fig. 2. Negative and positive ( $\geq 3$ P. perniciosus) catch sites, represented in an altitudinal range map.

cating very low probability of species presence) up to 1 (very high relative probability of the species being present). All other parameters were set to the default settings. Furthermore, we ran 50 sub-sample replicates to test the amount of variability in the model. To reduce issues related to overfitting and collinearity in the environmental variables, a subset of potential predictors was chosen from the full set in an initial explorative analysis. This entailed fitting several models using a single environmental layer at a time and comparing the predictive power of each variable as measured by the area under the curve (AUC). Furthermore, correlation among variables was tested using Pearson's correlation analysis (software IBM SPSS statistics 20). The more meaningful and predictive variables, among the highly correlated ones, were selected for inclusion in the model.

The final model was validated using both thresholddependent and threshold-independent methods. The AUC of the receiver operating characteristic (ROC) analysis is a threshold-independent method of evaluating model quality. The threshold-dependent evaluation was done based on dichotomising the continuous map outputs into presence and absence values using the minimum training presence and 10 percentile training presence thresholds (Pearson et al., 2007; Radosavljevic and Anderson, 2014) and then deriving tests statistics from the confusion matrix, i.e. positive predictive power (PPP), negative predictive power
(NPP), sensitivity (SE) and specificity (SP). The functional relationship between sand fly presence and the environmental variables was evaluated through inspection of the MaxEnt programme response curves. The relative importance of each environmental variable in the model was evaluated by jackknife tests of variable importance. Finally, we overlapped the model of $P$. perniciosus and the map of the municipalities with CanL autochthonous cases in the study area (Cassini et al., 2010) to verify visually any congruence of the predicted sand fly distributions with the known occurrence of CanL. The maps were constructed using Quantum GIS (www.qgis.org).

\section{Results}

\section{Entomological survey}

Sand flies were observed at 94 of 175 monitored sites $(54 \%)$. Overall, 6,144 sand flies were collected and identified as P.perniciosus ( $\mathrm{n}=3,797 ; 61.8 \%$ ), P. neglectus ( $\mathrm{n}=665 ; 10.8 \%), P$. papatasi $(\mathrm{n}=45$; $0.7 \%), P$. mascittii ( $\mathrm{n}=29 ; 0.5 \%$ ) and Sergentomyia minuta ( $\mathrm{n}=1,065 ; 17.3 \%) ; 543$ sandflies were not identified. P. perniciosus, which is a proven vector of CanL, was the most abundant species. The 60 positive sites ( $\geq 3$ P. perniciosus) used for ecological niche modelling, the negative sites and the altitudinal ranges are represented in Fig. 2. 


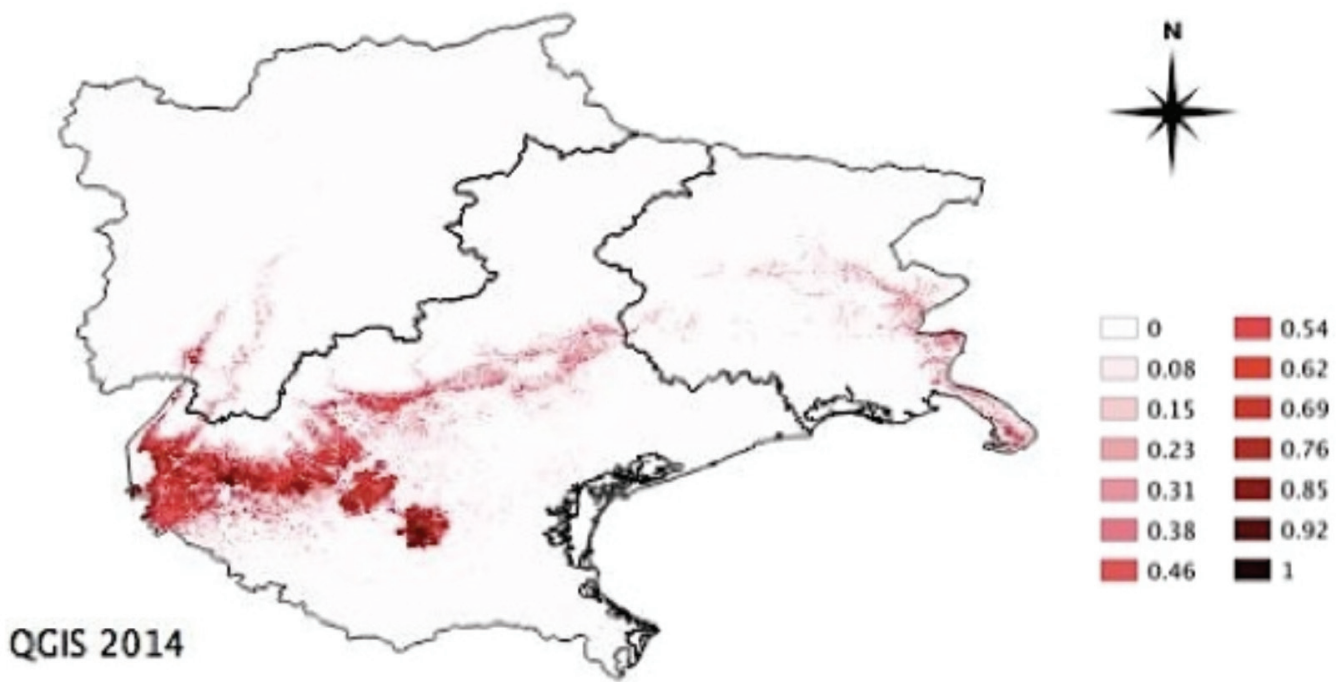

Fig. 3. The habitat suitability map of P. perniciosus in north-eastern Italy, obtained by the MaxEnt model.

\section{Ecological niche modelling}

Based on the exploratory analysis, the following environmental layers were selected for inclusion in the final model: altitude (DEM), CLC, NDVI winter, winter $\mathrm{LST}_{\text {night }}$, summer LST $\mathrm{T}_{\text {day }}$ and BIO 18.

Fig. 3 shows the habitat suitability map of P. perniciosus in north-eastern Italy, as predicted by the MaxEnt model. The overlap between habitat suitability area and municipalities with confirmed CanL autochthonous cases is shown in Fig. 4.
The model demonstrated a good predictive performance: the test AUC was $0.931(\mathrm{SD}=0.026)$ and the average test AUC for the replicate runs was 0.949 ( $\mathrm{SD}=0.022)$, showing acceptable model variability. The model obtained a high SE and NPP, 98.3\% and 91.7\% (using the minimum training presence threshold) and $90.0 \%$ and $89.9 \%$ (using the $10 \%$ training presence threshold), respectively.

The jackknife test of variable importance shows that altitude (DEM) was the most influential variable when a model is created using each variable in isolation,

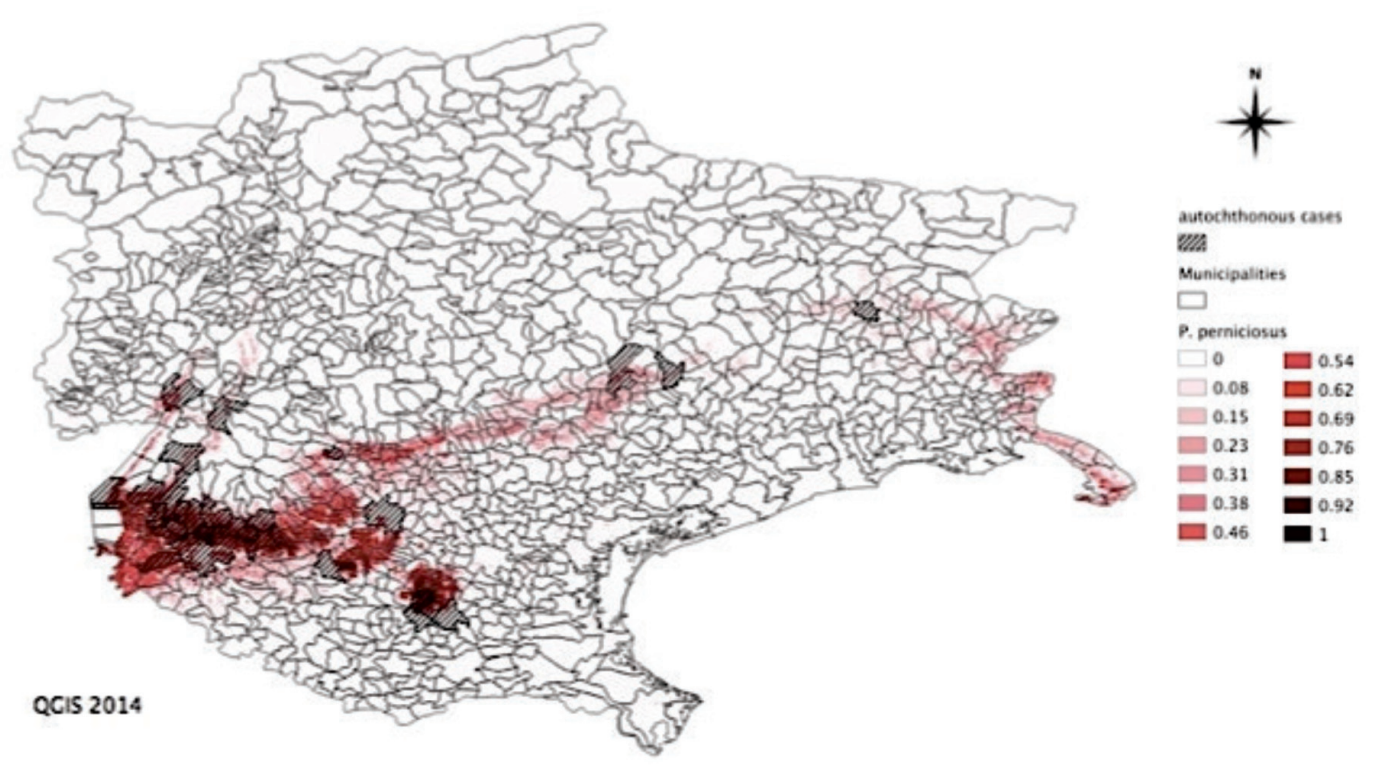

Fig. 4. Potential distribution of $P$. perniciosus in north-eastern Italy and municipality with CanL autochthonous cases. 


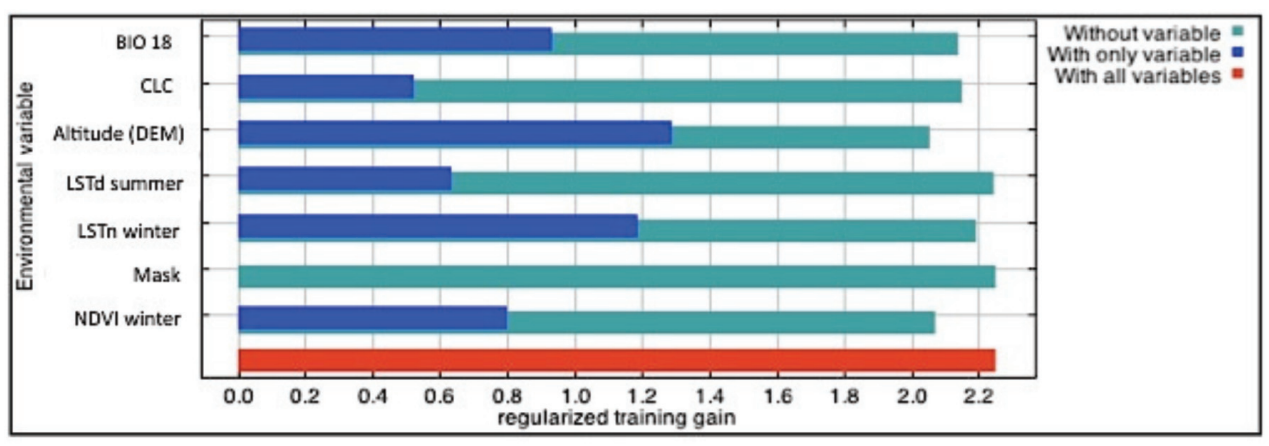

Fig. 5. The results of jackknife test of regularised training gain for P. perniciosus.

indicating that it contributes strongly to the model development. The model gain is minimally decreased by the exclusion of all variables in turn. This is a reflection that none of these variables in isolation are overwhelmingly contributing to this model (Fig. 5). The set of response curves produced by the software, by generating a model using only the corresponding variable, are shown in Fig. 6.
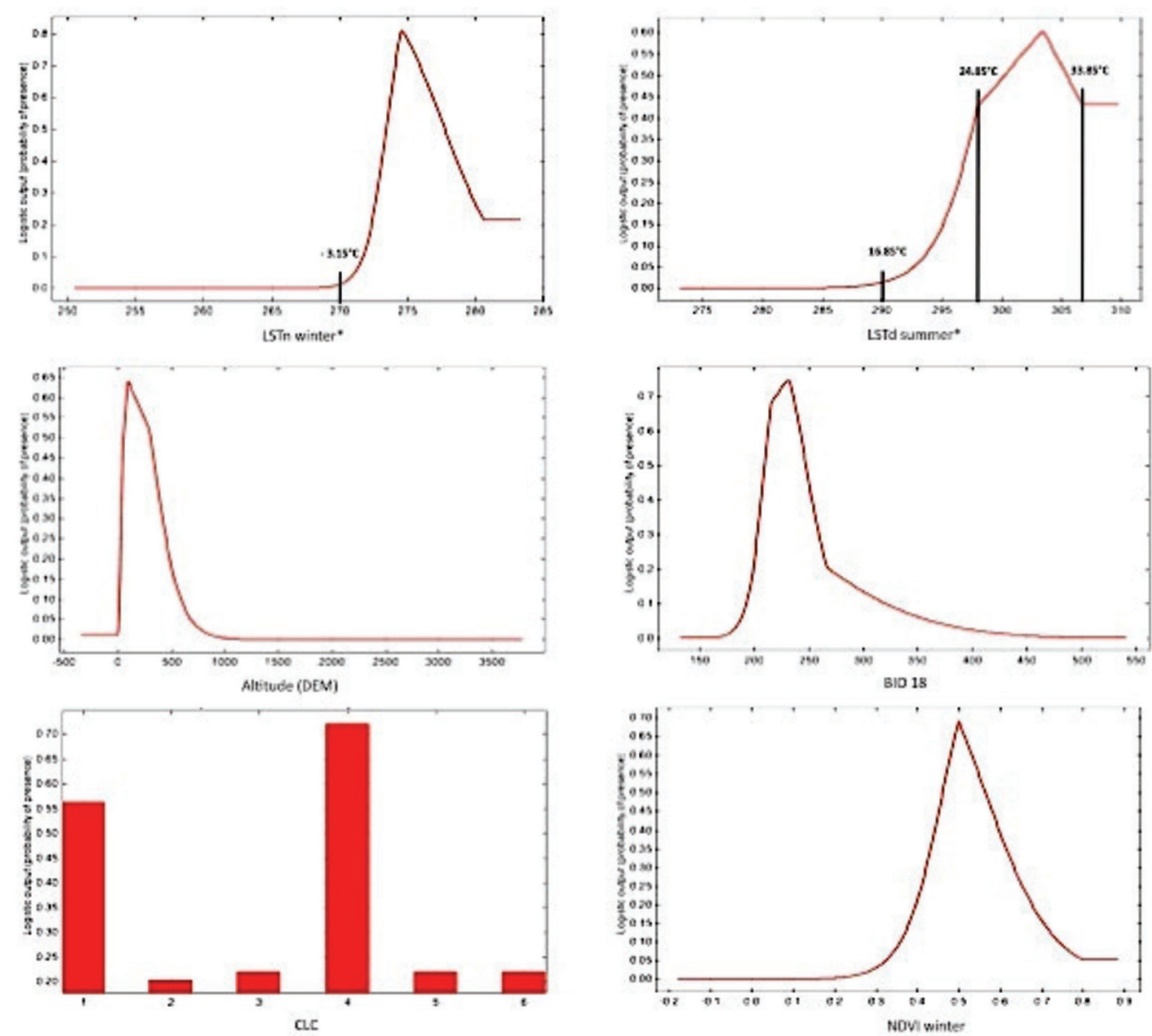

The temperature are represented in Kelvin

Fig. 6. Set of response curves, created by generating a model using only the corresponding variable. 
areas, with temperate climate, high vegetation cover and moderate rainfall) consistent with the biological and ecological requirements of the species. Furthermore, the prediction is consistent with the known distribution of $P$. perniciosus and the main risk areas overlap well with the known distribution of CanL foci in the study area (Fig. 4).

The model demonstrates a good predictive power and capability to identify the observed presence records as well as areas not suitable for the species, as evidenced by a high SE and NPP. It's important to note that the threshold (cut-off value for presence/absence) should be chosen according to the type of data available and to the aims of the study. Our purpose was to identify an area as large as possible of potentially suitable habitat, maximising the number of observed presence correctly predicted; accordingly the thresholds were set at a relatively low value of probability of occurrence (Pearson, 2008; Pearson et al., 2007). In fact, sand flies are not a very mobile species, therefore dispersal to unoccupied suitable habitats for their survival and establishment may be hindered by geographical constraints, dispersal limitation or other limiting anthropic factors, not considered in the model.

The curves show that the model seems to be able to identify the climatic and environmental conditions suitable for P. perniciosus. The highest relative probability of presence values was predicted in hilly areas, between 100 and $300 \mathrm{~m}$ above MSL (Fig. 6), in line with previous studies (Biocca et al., 1977; Maroli et al., 2008; Cassini et al., 2010). The variable that contributed most to the model's predictive power was altitude. However, as DEM is closely related to the topography of the study area, the altitude it describes may not be the most appropriate variable to use for model extrapolation to different regions.

Areas with night-time winter temperatures below $-4{ }^{\circ} \mathrm{C}$, were predicted to be unsuitable for sand fly presence, which must be considered a major limiting factor for the larval stages survival during the diapauses. The highest relatively probability of presence was instead predicted in areas where day-time summer temperature was between $25^{\circ} \mathrm{C}$ and $33^{\circ} \mathrm{C}$, whereas the lower limit temperature was predicted at $16.5^{\circ} \mathrm{C}$. Considering the sand fly biology, the summer temperature can be considered an important parameter for the accomplishment of the life-cycle during the activity season and the temperature optimal range encountered in the present study is in agreement with experimental data (Theodor, 1936; Dolmatova and Demina, 1968; Maroli, 1983; Maroli et al., 1987).

The results indicate that sand flies seem to prefer areas with high winter vegetation cover (NDVI) that could be related to the survival of the larvae with NDVI representing a surrogate for soil moisture. The response curve of the relationship between probability of presence and the precipitation during the warmest quarter (BIO18) shows that P. perniciosus seems to prefer moderate rainfall habitats. CLC did not play a significant role in the prediction model of sand fly habitat suitability. This could, however, be an artefact related to the use of only the highest CLC hierarchical level, which may not discriminate the land use characteristics sufficient for sand fly prediction.

A critical aspect of the developed model is that the entomological data are based on monitoring activities performed over many years and with different aims. Consequently, species distribution could have changed during the period of the study and all areas were not equally monitored. However, a presence record is a confirmed record (unlike an absence record) and MaxEnt, which uses presence-only input data, represents one of the best methods to deal with irregular databases, which is the case for most of the retrospective entomological databases. In the future, data from monitoring conducted in a delimited time window and distributed uniformly may help to refine the model. Furthermore, new sites to be monitored in the coming years may constitute an independent dataset, which is essential in order to achieve a fuller validation of the model's predictive power.

In conclusion, the visualisation of the geographical distribution patterns of vector species in ecological space, using GIS tools and ENM, based on remotely sensed environmental data, has been demonstrated, in the current study, to be a useful tool for the understanding of the ecological requirements of the vectors sand fly and of potential geographical distribution of CanL. The final maps produced by this study may help local and national health authorities to design future control and surveillance strategies, with a risk-based allocation of resources and to concentrate the control activities aimed to reduce CanL prevalence only in area at higher risk (Cassini et al., 2013). Furthermore, the methodological approach presented here may serve as a model for studies in neighbouring regions.

\section{References}

Alexander B, 2000. Sampling methods for phlebotomine sandflies. Med Vet Entomol 14, 109-122.

Belen A, Alten B, 2011. Seasonal dynamics and altitudinal distributions of sand fly (Diptera: Psychodidae) populations in a cutaneous leishmaniasis endemic area of the Cukurova region 
of Turkey. J Vector Ecol 36, S87-S94.

Biocca E, Coluzzi A, Costantini R, 1977. Osservazioni sulla attuale distribuzione dei flebotomi italiani e su alcuni caratteri morfologici differenziali tra le specie del sottogenere Phlebotomus. Parassitologia 19, 19-32.

Bogdan C, Schonian G, Banuls AL, Hide M, Pratlong F, Lorenz E, Rollinghoff M, Mertens R, 2001. Visceral leishmaniasis in a german child who had never entered a known endemic area: case report and review of the literature. Clin Infect Dis 32, 302-306.

Cassini R, Natale A, Pozzato N, Lorenzetto M, Capelli G, 2010. La progressione della leishmaniosi canina verso nord: una malattia da tenere sotto controllo. Summa - Animali da Compagnia 5, 9-16.

Cassini R, Signorini M, Frangipane di Regalbono A, Natale A, Montarsi F, Zanaica M, Brichese M, Simonato G, Borgato S et al., 2013. Preliminary study of the effects of preventive measures on the prevalence of canine leishmaniosis in a recently established focus in northern Italy. Vet Ital 49, 157-161.

Chamaille L, Tran A, Meunier A, Bourdoiseau G, Ready P, Dedet J, 2010. Environmental risk mapping of canine leishmaniasis in France. Parasit Vectors 3, 31.

Cross ER, Hyams KC, 1996. The potential effect of global warming on the geographic and seasonal distribution of Phlebotomus papatasi in southwest Asia. Environ Health Perspect 104, 724-727.

Dereure J, Vanwambeke SO, Malé P, Martinez S, Pratlong F, Balard Y, Dedet JP, 2009. The potential effects of global warming on changes in canine leishmaniasis in a focus outside the classical area of the disease in southern France. Vector Borne Zoonotic Dis 9, 687-694.

Dolmatova AV, Demina NA, 1968. Les Phlébotomes (Phlebotominae) et les maladies qu'ils transmettent. Relazione tecnica, ORSTOM Bulletin de liaison.

Elith J, Graham CH, Anderson RP, Dudík M, Ferrier S, Guisan A, Hijmans RJ, Huettmann F, Leathwick JR, Lehmann A et al., 2006. Novel methods improve prediction of species' distributions from occurrence data. Ecography 29, 129-151.

Farkas R, Tánczos B, Bongiorno G, Maroli M, Dereure J, 2011. First surveys to investigate the presence of canine leishmaniasis and its phlebotomine vectors in Hungary. Vector Borne Zoonotic Dis 11, 823-834.

Ferroglio E, Maroli M, Castaldo S, Mignone W, Rossi L, 2005. Canine leishmaniasis in Italy. Emerg Infect Dis 11, 1618-1620. Ferroglio E, Maroli M, Castaldo S, Trisciuoglio A, Raimondo C, Veysendaz E, Saracco M, Rossi L, 2002. Survey of phlebotomine sandflies in north-west Italy. Parassitologia 44, 68.

Fischer D, Moeller P, Thomas SM, Naucke TJ, Beierkuhnlein C, 2011a. Combining climatic projections and dispersal ability: a method for estimating the responses of sandfly vector species to climate change. PLoS Negl Trop Dis 5, e1407.

Fischer D, Thomas SM, Beierkuhnlein C, 2010. Temperature- derived potential for the establishment of phlebotomine sandflies and visceral leishmaniasis in Germany. Geospat Health 5, 59-69.

Fischer D, Thomas SM, Beierkuhnlein C, 2011b. Modelling climatic suitability and dispersal for disease vectors: the example of a phlebotomine sandfly in Europe. Procedia Environ Sci 7, 164-169.

Gebre-Michael T, Malone JB, Balkew M, Ali A, Berhe N, Hailu A, Herzi AA, 2004. Mapping the potential distribution of Phlebotomus martini and P. orientalis (Diptera: Psychodidae), vectors of kala-azar in East Africa by use of geographic information systems. Acta Trop 90, 73-86.

Haeberlein S, Fischer D, Thomas SM, Schleicher U, Beierkuhnlein C, Bogdan C, 2013. First assessment for the presence of phlebotomine vectors in Bavaria, southern Germany, by combined distribution modeling and field surveys. PLoS One 8, e81088.

Hernandez PA, Graham CH, Master LL, Albert DL, 2006. The effect of sample size and species characteristics on performance of different species distribution modeling methods. Ecography 29, 773-785.

Loiselle BA, Jørgensen PM, Consiglio T, Jiménez I, Blake JG, Lohmann LG, Montiel OM, 2008. Predicting species distributions from herbarium collections: does climate bias in collection sampling influence model outcomes? J Biogeogr 35, 105 116.

Maroli M, 1983. Laboratory colonization of Phlebotomus perfiliewi (Parrot). Trans R Soc Trop Med Hyg 77, 876-877.

Maroli M, Feliciangeli MD, Bichaud L, Charrel RN, Gradoni L, 2012. Phlebotomine sandflies and the spreading of leishmaniases and other diseases of public health concern. Med Vet Entomol 27, 123-147.

Maroli M, Fiorentino S, Guandalini E, 1987. Biology of a laboratory colony of Phlebotomus perniciosus (Diptera: Psychodidae). J Med Entomol 24, 547-551.

Maroli M, Rossi L, Baldelli R, Capelli G, Ferroglio E, Genchi C, Gramiccia M, Mortarino M, Pietrobelli M, Gradoni L, 2008. The northward spread of leishmaniasis in Italy: evidence from retrospective and ongoing studies on the canine reservoir and phlebotomine vectors. Trop Med Int Health 13, 256-264.

Morosetti G, Bongiorno G, Beran B, Scalone A, Moser J, Gramiccia M, Gradoni L, Maroli M, 2009. Risk assessment for canine leishmaniasis spreading in the north of Italy. Geospat Health 4, 115-127.

Mughini-Gras L, Mulatti P, Severini F, Boccolini D, Romi R, Bongiorno G, Khoury C, Bianchi R, Montarsi F, Patregnani T, et al., 2013. Ecological niche modelling of potential West Nile virus vector mosquito species and their geographical association with equine epizootics in Italy. Ecohealth 11, 120-132.

Naucke TJ, Lorentz S, Rauchenwald F, Aspock H, 2011. Phlebotomus (Transphlebotomus) mascittii Grassi, 1908, in Carinthia: first record of the occurrence of sandflies in Austria 
(Diptera: Psychodidae: Phlebotominae). Parasitol Res 109, 1161-1164.

Pearson RG, 2008. Species' Distribution Modeling for Conservation Educators and Practitioners. Synthesis. American Museum of Natural History. Available at: http://academic.uprm.edu/ jchinea/UIP-MAPR/refs/modelos/pearson2008.Pdf (Accessed on June 2014).

Pearson RG, Raxworthy CJ, Nakamura M, Peterson AT, 2007. Predicting species distribution from small numbers of occurrence records: a test case using cryptic geckos in Madagascar. J Biogeogr 34, 102-117.

Pérez J, Virgen A, Rojas JC, Rebollar-Téllez EA, Alfredo C, Infante F, Mikery O, Marina CF, Ibáñez-Bernal S, 2013. Species composition and seasonal abundance of sandflies (Diptera: Psychodidae: Phlebotominae) in coffee agroecosystems. Mem Inst Oswaldo Cruz 109, 80-86.

Phillips SJ, Anderson RP, Schapire RE, 2006. Maximum entropy modeling of species geographic distributions. Ecol Modell 190, 231-259.

Phillips SJ, Dudík M, 2008. Modeling of species distributions with Maxent: new extensions and a comprehensive evaluation. Ecography 31, 161-175.

Poglayen G, Marangon S, Manca MG, Capelli G, Dalla Pozza M, Casati D, Vantini E, Bressan G, Passarini G, 1997. A new outbreak of canine leishmaniosis in the North-East of Italy. Acta Parasit Turcica 21, 143.

Radosavljevic A, Anderson RP, 2014. Making better MAXENT models of species distributions: complexity, overfitting and evaluation. J Biogeogr 41, 629-643.

Ready PD, 2008. Leishmaniasis emergence and climate change. Rev Sci Tech 27, 399-412.

Romi R, Khoury C, Bigliocchi F, Maroli M, 1994. Schede guida su acari e insetti di interesse sanitario. Rapp ISTISAN 94/8, 33-42.

Rossi L, Ferroglio E, Guiso P, Ferrasi P, Pancaldi P, 1999. Segnalazione di un focolaio di leishmaniosi canina sulla collina torinese. Medicina Veterinaria Preventiva 20, 20.

Signorini M, Drigo M, Marcer F, Frangipane di Regalbono A, Gasparini G, Montarsi F, Pietrobelli M, Cassini R, 2013. Comparative field study to evaluate the performance of three different traps for collecting sand flies, in north-eastern Italy. J Vector Ecol 38, 374-378.

Theodor O, 1936. On the relation of Phlebotomus papatasi to the temperature and humidity of the environment. Bull Entomol Res 36, 653- 671.

Wang X, Xie H, Guan H, Zhou X, 2007. Different responses of MODIS-derived NDVI to root-zone soil moisture in semi-arid and humid regions. J Hydrol 340, 12-24. 